\title{
Influence of convection and aerosol pollution on ice cloud particle effective radius
}

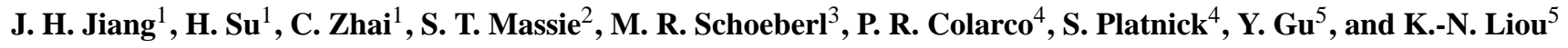 \\ ${ }^{1}$ Jet propulsion Laboratory, California Institute of Technology, Pasadena, California, USA \\ ${ }^{2}$ National Center for Atmospheric Research, Boulder, Colorado, USA \\ ${ }^{3}$ Science and Technology Corporation, Columbia, Maryland, USA \\ ${ }^{4}$ NASA Goddard Space Flight Center, Greenbelt, Maryland, USA \\ ${ }^{5}$ Department of Atmospheric and Oceanic Sciences, University of California, Los Angeles, USA
}

Received: 28 August 2010 - Published in Atmos. Chem. Phys. Discuss.: 7 October 2010

Revised: 30 December 2010 - Accepted: 10 January 2011 - Published: 17 January 2011

\begin{abstract}
Satellite observations show that ice cloud effective radius $\left(r_{\mathrm{e}}\right)$ increases with ice water content (IWC) but decreases with aerosol optical thickness (AOT). Using leastsquares fitting to the observed data, we obtain an analytical formula to describe the variations of $r_{\mathrm{e}}$ with IWC and AOT for several regions with distinct characteristics of $r_{\mathrm{e}}$-IWCAOT relationships. As IWC directly relates to convective strength and AOT represents aerosol loading, our empirical formula provides a means to quantify the relative roles of dynamics and aerosols in controlling $r_{\mathrm{e}}$ in different geographical regions, and to establish a framework for parameterization of aerosol effects on $r_{\mathrm{e}}$ in climate models.
\end{abstract}

\section{Introduction}

It is well known that aerosols can cause changes in cloud number concentration and therefore alter cloud particle size, which can result in changes of cloud lifetime, reflectance, and precipitation (e.g. Twomey, 1977; Albrecht, 1989; Lohmann and Feichter, 2005; Penner et al., 2006). To date, quantification of the indirect effects of aerosols on climate remains a challenging problem. One difficulty is to separate dynamic effects, for example, the convective updraft strength, from aerosol microphysical effects. Inadequate understanding of the relationship between microphysical and dynamical processes contributes to large uncertainties in model simulations of aerosol effects on clouds, precipitation and climate.

Correspondence to: J. H. Jiang

(jonathan.h.jiang@jpl.nasa.gov)
Recent studies (e.g. Jiang et al., 2008, 2009; Su et al., 2011) using collocated Aura satellite's Microwave Limb Sounder (MLS) and Aqua satellite's Moderate-resolution Imaging Spectroradiometer (MODIS) observations showed reduction of upper tropospheric (UT) ice cloud effective radius $\left(r_{\mathrm{e}}\right)$ in polluted clouds, defined by collocated carbon monoxide (CO) measurements higher than a certain threshold value. The enhanced $\mathrm{CO}$ values are positively correlated with aerosol optical thickness (AOT) for a number of geographical regions and seasons. Jiang et al. $(2008,2009)$ also showed that $r_{\mathrm{e}}$ generally increases with convective intensity indicated by ice water content (IWC), as stronger convection produces more condensates and larger cloud particles. For different regions and seasons, the variations of $r_{\mathrm{e}}$ with IWC and CO (AOT) are different. Characterizing the regional differences of dynamic and aerosol effects quantitatively is needed for models to accurately simulate aerosolcloud interactions.

Traditionally, the ice cloud particle size distribution is parameterized as a function of IWC following a gamma distribution (e.g. Matrosov et al., 1994; Evans and Stephens, 1995) or a bimodal distribution (e.g. Mitchell et al., 1996; Platt, 1997; McFarquhar and Heymsfield, 1997), neither of which takes into account the effect of aerosol on $r_{\mathrm{e}}$ (i.e. the first indirect effect of aerosols on clouds). In this paper, we use least squares fitting to the observations and derive an analytical formula to describe the $r_{\mathrm{e}}$ variations with convection and aerosol intensities in different geographical regions and seasons. It expands the previous $r_{\mathrm{e}}-$ IWC relation to include the dependency of $r_{\mathrm{e}}$ on AOT as well. This formula intends to provide a framework to quantify the relative effects of dynamics and aerosols on $r_{\mathrm{e}}$, and to parameterize the first indirect effects of aerosols for use in climate models. 


\section{Data and approach}

For this study, the MODIS $r_{\mathrm{e}}$ and AOT measurements are from Aqua MODIS MYD08-D3 and MYD04-L2 data sets, respectively (Platnick et al., 2003; Remer et al., 2005). The MLS IWC is from MLS Version 2.2 Level 2 data (Wu et al., 2008). The MODIS and MLS measurements are collocated by averaging the MODIS data onto the MLS footprints (Jiang et al., 2009). Although the MODIS AOT data are usually missing in the cloudy regions, the MODIS measurements have much higher horizontal resolution $(\sim 10 \mathrm{~km} \times 10 \mathrm{~km})$ than the MLS measurements $(\sim 300 \mathrm{~km}$ along track and $\sim 7 \mathrm{~km}$ cross track), thus the AOT data are available in about half of the data in which MLS detects cloud (i.e when IWC $>0$ ).

The MODIS $r_{\mathrm{e}}$ measurement pertains to the top of cirrus clouds. Platnick (2000) studied weighting or probability distribution function (PDF) of the penetration distribution in optical depth units from water cloud-top. The same methods in the Platnick (2000) have been used for ice clouds by Zhang et al. (2010), which estimated the MODIS $r_{\mathrm{e}}$ retrieval is mostly sensitive to $\sim 0.1$ to 0.2 optical depth from cloud top (approximate $<\sim 1-2 \mathrm{~km}$, depending on how dense the clouds are). Different from MODIS, MLS retrieves heightresolved ice clouds above $215 \mathrm{hPa}$. MLS IWC measurements are vertically distributed at the pressure levels between 215 and $68 \mathrm{hPa}$, with a $3-4 \mathrm{~km}$ vertical resolution. Given that only the cloud top $r_{\mathrm{e}}$ is available from MODIS, we limit the analysis to those $r_{\mathrm{e}}$ measurements when IWC at $215 \mathrm{hPa}$ is detectable by MLS, where clouds are likely associated with deep convection. We examine the cloud top $r_{\mathrm{e}}$ relationship as a function of the column aerosol loading (indicted by AOT) and convective strength (indicated by MLS IWC at $215 \mathrm{hPa}$ ) under the premise that the influence of lower level aerosols on clouds is propagated to deep convective cloud tops (e.g. Sherwood, 2002). For parameterization of $r_{\mathrm{e}}$ in climate models, it would be desirable to describe $r_{\mathrm{e}}$ as a function of aerosol concentration and cloud water content (CWC) at each vertical height. However, due to the limitation of the data, the current study aims to provide a heuristic framework for future height-resolved analysis. The bulk relationships obtained here are insightful for understanding of the dynamics and aerosol effects on convective cloud particle sizes.

We also use the outgoing longwave radiation (OLR) data from GEOS-5 (Goddard Earth Observation Systems, Version 5) analysis to validate that MLS IWC at $215 \mathrm{hPa}$ is a good index for convection. The GEOS-5 analyses are "snapshots" of the atmospheric state produced four times daily (at 00:00 Z, 06:00 Z, 12:00 Z, and 18:00 Z) using optimal combinations of model forecasts and many observations (Rienecker et al., 2008) via the Gridpoint Statistical Interpolation (GSI) technique of Wu et al. (2002). For this study, the GEOS-5 OLR data, which have a $0.5^{\circ} \times 0.67^{\circ}$ latitude-longitude resolution, are sampled onto the MLS footprints (Jiang et al., 2010) to match the observations.
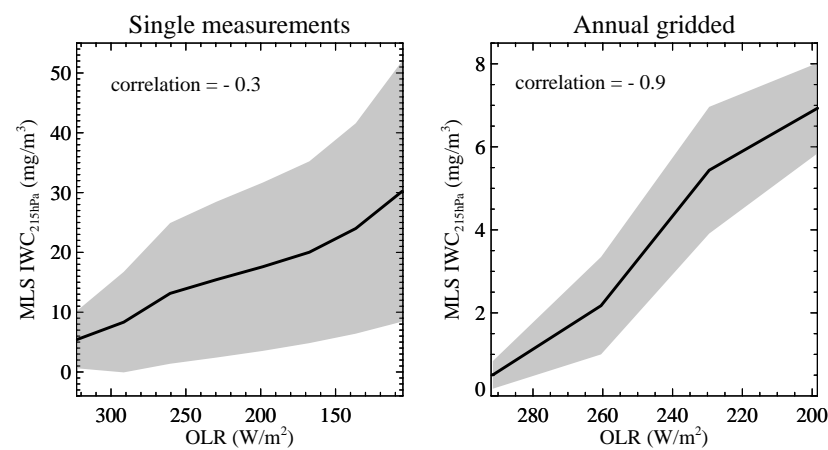

Fig. 1. Left column: The black curve is the MLS measured IWC at $215 \mathrm{hPa}$ binned as a function of collocated GEOS-5 OLR. All single MLS IWC measurements between August 2004 and July 2008 in the tropical region $\left(30^{\circ} \mathrm{S}-30^{\circ} \mathrm{N}\right)$ are used. The GEOS-5 data are sampled onto the MLS footprints. The standard deviations of the data are indicated by the gray shaded area. Right column: Same as left column except for gridded ( $8^{\circ}$ longitude by $4^{\circ}$ degree latitude) data averaged for the 4 years.

The level of convective detrainment is approximately $\sim 200 \mathrm{hPa}$ (e.g. Kazuaki et al., 2004; Devasthale and Fueglistaler, 2010), and the amount of ice water at this level is proportional to convective intensity. MLS IWC has been found to be indicative of convective strength. Liu (2007) showed in detail that MLS detected ice clouds are geographically and seasonally correlated with deep convection as inferred from the TRMM brightness temperature $<210 \mathrm{~K}$. He used MLS IWC at $100 \mathrm{hPa}$ and $147 \mathrm{hPa}$ in particular. Our analysis (Jiang et al., 2007, 2010; Su et al., 2006) showed $215 \mathrm{hPa}$ IWC correlates with convective intensity. Figure 1 shows the relationship between the MLS IWC measurements at $215 \mathrm{hPa}$ and the GEOS-5 OLR for the tropical region $\left(30^{\circ} \mathrm{S}\right.$ to $\left.30^{\circ} \mathrm{N}\right)$. Consistent with previous studies, the $215 \mathrm{hPa}$ IWC and the OLR have good correlations on instantaneous measurements and grid means, and thus can be used as an index for convective strength, approximately.

The reason we use IWC, not OLR, in the empirical fitting (described later in Sect. 4) follows conventional parameterization for $r_{\mathrm{e}}$, which is directly related to the mass density of ice particles. Previous work such as McFarquhar and Heymsfield (1997), explicitly employed the dependence of $r_{\mathrm{e}}$ on IWC, which inspired us to expand that relationship to include aerosol dependence. Using IWC, rather than OLR, to fit $r_{\mathrm{e}}$ also helps to extend our empirical fitting framework from cloud-top $r_{\mathrm{e}}$ to height-resolved $r_{\mathrm{e}}$ in the future, when both vertically resolved $r_{\mathrm{e}}$ and IWC are available. 


\section{Observed relationships}

We define the convective index (CONV) as

$\mathrm{CONV}_{i}=\mathrm{IWC}_{i} / \overline{\mathrm{IWC}}$

where $\mathrm{IWC}_{i}$ represents each single MLS $215 \mathrm{hPa}$ IWC measurement and $\overline{\text { IWC }}$ is the mean of all the $215 \mathrm{hPa}$ IWC samples in the region.

Next, we examine the relationships among the MLS CONV index and MODIS measurements of ice cloud $r_{\mathrm{e}}$ and AOT from August 2004 to July 2008 between $50^{\circ} \mathrm{S}$ and $50^{\circ} \mathrm{N}$. Figure $2 \mathrm{a}$ shows the MODIS $r_{\mathrm{e}}$ binned according to the CONV index. The thick black curve is the average $r_{\mathrm{e}}$ vs. CONV, and it includes all values of AOT. It can be seen that when CONV is relatively small, $r_{\mathrm{e}}$ increases approximately linearly with IWC. When CONV is greater than $\sim 1$, the increase of $r_{\mathrm{e}}$ with CONV becomes slower or saturated as the maximum $r_{\mathrm{e}}$ may be limited by the settling velocities of the ice particles. The influence of aerosol on $r_{\mathrm{e}}$ is illustrated by grouping the $r_{\mathrm{e}}$ data for polluted clouds with AOT $>0.4$ (thin black curve) and for clean clouds having AOT $<0.05$ (blue curve). The $r_{\mathrm{e}}$ for the polluted clouds is about $2-4 \mu \mathrm{m}$ smaller than the $r_{\mathrm{e}}$ for the clean clouds. Note that the clean cloud $r_{\mathrm{e}}$ increases faster with CONV than the polluted cloud $r_{\mathrm{e}}$.

Figure $2 \mathrm{~b}$ shows the relation of $r_{\mathrm{e}}$ to AOT. For $0<\mathrm{AOT}<\sim 0.1, r_{\mathrm{e}}$ quickly increases with AOT. When $\mathrm{AOT}>0.1, r_{\mathrm{e}}$ decreases at a rate of about $0.5 \mu \mathrm{m}$ per 0.1 increase of AOT until AOT $\sim 0.5$, then the $r_{\mathrm{e}}$ decreasing rate becomes slower and stays approximately constant.

The dependence of $r_{\mathrm{e}}$ on CONV and AOT is further illustrated by the Bi-Variate Composite (BVC) plot of the $r_{\mathrm{e}}$-CONV-AOT relation (Fig. 2c), in which the MODIS $r_{\mathrm{e}}$ data are binned according both to the MLS CONV and the MODIS AOT values. About 150000 collocated MODIS and MLS measurements from August 2004 to July 2008 between $50^{\circ} \mathrm{S}$ to $50^{\circ} \mathrm{N}$ are used for the plot. The dotted lines show the occurrence frequency for each CONV-AOT pair. The BVC figure shows that $r_{\mathrm{e}}$ increases with CONV but decreases with AOT: the largest $r_{\mathrm{e}}$ resides where the convection $(\mathrm{CONV})$ is largest and pollution (AOT) is lowest, i.e. strong convection in a clean environment. At constant CONV, the $r_{\mathrm{e}}$ decreases with increasing AOT, suggesting an influence of aerosol loading on the cloud particle size. At constant AOT, $r_{\mathrm{e}}$ increases with CONV until CONV approaches $\sim 1$. At the large CONV values (CONV $>\sim 1), r_{\mathrm{e}}$ becomes approximately constant when AOT is $<\sim 0.3$, but decreases with IWC in high polluted cases (AOT $>\sim 0.3$ ).

\section{Empirical fitting}

In order to obtain a simple mathematical expression for the above observed $r_{\mathrm{e}}$-CONV-AOT relation, we assume that the dependence of $r_{\mathrm{e}}$ on CONV and AOT is decoupled, i.e., $r_{\mathrm{e}}=r_{\text {aot }} \cdot r_{\text {conv }}$, where $r_{\text {conv }}$ denotes how cloud particle effective radius changes with CONV and $r_{\text {aot }}$ represents the effect of aerosols on $r_{\mathrm{e}}$. This assumption is chosen for its simplicity to capture the observed $r_{\mathrm{e}}$-CONV-AOT relations, although we recognize that AOT and CONV are in fact not independent. We write

$r_{\mathrm{conv}}=[1-\exp (-\mathrm{CONV} / \alpha)] \cdot \exp (-\beta \mathrm{CONV})$,

where $\alpha$ and $\beta$ are the parameters that control how fast $r_{\mathrm{e}}$ changes with CONV. The reduction of $r_{\mathrm{e}}$ by aerosol effect is assumed to follow a power-law:

$r_{\mathrm{aot}}=\varepsilon \cdot \mathrm{AOT}^{\eta}$

where $\eta$ is a parameter that determines how strong the aerosol effect is, and $\varepsilon$ is a scaling constant. A superposition of Eqs. (2) and (3) yields

$r_{\mathrm{e}}=\varepsilon \cdot \mathrm{AOT}^{\eta} \cdot[1-\exp (-\mathrm{CONV} / \alpha)] \cdot \exp (-\beta \mathrm{CONV})$.

We then perform two dimensional (2-D) least-squares fitting to the observed data with the empirical formula (4), i.e., to determine the parameters $\alpha, \beta, \eta$, and $\varepsilon$, through minimizing the following cost function

$\underset{\alpha, \beta, \eta, \varepsilon}{\operatorname{cost}}=\sum_{i, j}\left[r_{\mathrm{e}}^{i, j}-r_{\mathrm{e}}\left(\mathrm{CONV}^{i}, \mathrm{AOT}^{j}, \alpha, \beta, \eta, \varepsilon\right)\right]^{2}$

where $r_{\mathrm{e}}^{i, j}$ (in $\mu \mathrm{m}$ ) is the mean $r_{\mathrm{e}}$ corresponding to the $i$ th CONV-bin and $j$-th AOT-bin. The CONV ${ }^{i}$ is the mean CONV in the $i$-th CONV-bin and $\mathrm{AOT}^{j}$ is the mean AOT in the $j$-th AOT-bin. Figure $2 \mathrm{c}$ shows an example of such $r_{\mathrm{e}}$, CONV, and AOT relationship to be fitted. For our leastsquares fitting computation, there are 24 bins of AOT between 0.0 and 1 , and the CONV are computed using Eq. (1) from 24 bins of IWC between 0.01 and $100 \mathrm{mg} \mathrm{m}^{-3}$.

The least-square fittings are computed by using four years of MLS IWC and MODIS $r_{\mathrm{e}}$ and AOT measurements. The results of the fitted parameters for global (LON: $0^{\circ}-360^{\circ}$; LAT: $50^{\circ} \mathrm{S}-50^{\circ} \mathrm{N}$ ) and five different regions are given in $\mathrm{Ta}-$ ble 1 . The choice of the five regions is based on the previous study of Jiang et al. (2009), where ice cloud particle sizes in these regions were shown to correlate with aerosol loadings. These regions are: South America (LON: $270^{\circ}-340^{\circ}$; LAT: $40^{\circ} \mathrm{S}-10^{\circ} \mathrm{N}$ ); Southern Africa (LON: $0^{\circ}-55^{\circ}$; LAT: $35^{\circ} \mathrm{S}-$ $0^{\circ}$ ); Northern Africa (LON: $-10^{\circ}-45^{\circ}$; LAT: $0^{\circ} \mathrm{S}-25^{\circ} \mathrm{N}$ ); South Asia (LON: $70^{\circ}-120^{\circ}$; LAT: $10^{\circ} \mathrm{S}-15^{\circ} \mathrm{N}$ ); and East Asia (LON: $90^{\circ}-180^{\circ}$; LAT: $20^{\circ}-45^{\circ} \mathrm{N}$ ).

Substituting the fitted parameters into Eq. (4), we obtain $r_{\mathrm{e}}(\mu \mathrm{m})$ as functions of CONV and AOT for all of the above mentioned geographical regions. These empirical model results are plotted in Fig. 3 along with the observations. The $\chi^{2} / \mathrm{DOF}$ (degrees of freedom) listed in Table 1 illustrates the convergence of the fitting for different regions. The closer is the value of $\left(\chi^{2} / \mathrm{DOF}\right)$ to 1 (or less), the better is the fitting. We found that although all fittings converge after $\sim 20$ 
(a)

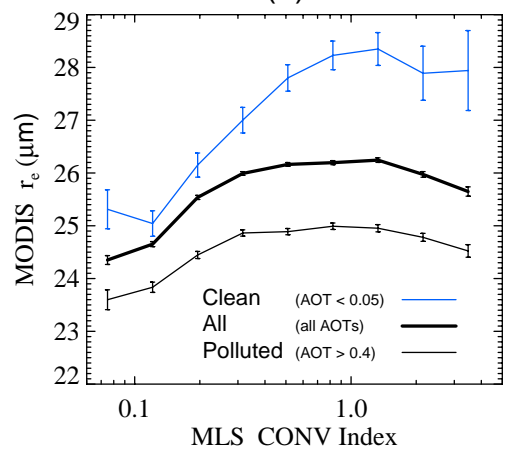

(b)

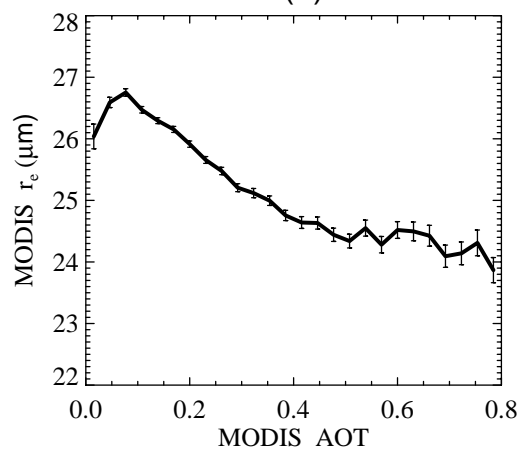

(c)

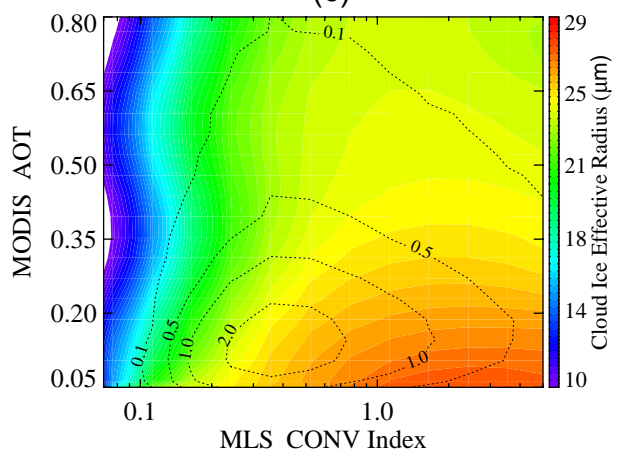

Fig. 2. (a): MODIS measured ice cloud $r_{\mathrm{e}}$ binned according to CONV, based on MLS IWC at $215 \mathrm{hPa}$. The thick black curve is the average $r_{\mathrm{e}}$ as a function of CONV using all values of AOT. The blue curve is for data with AOT $<0.05$ and the thin black curve is for data in heavily polluted environment with AOT > 0.4. (b): MODIS $r_{\mathrm{e}}$ binned according to the MODIS AOT measurements. (c): A Bi-Variate Composite (BVC) plot of the $r_{\mathrm{e}}$-CONV-AOT relation, in which the MODIS $r_{\mathrm{e}}$ data are binned according to both MLS IWC and MODIS AOT. The dotted-lines are the occurrence frequency for each CONV-AOT bin. All collocated MODIS and MLS measurements from August 2004 to July 2008 between $50^{\circ} \mathrm{S}$ to $50^{\circ} \mathrm{N}$ are used for the plot. The error bars in (a) and (b) denote the standard errors $(\sigma / \sqrt{N})$ of the bin average.

Table 1. Values of the empirical fitting parameters in Eq. (4) for various regions. The least-square fits are computed using IWC $\left(\mathrm{mg} \mathrm{m}^{-3}\right)$ measured by MLS, and $r_{\mathrm{e}}(\mu \mathrm{m})$ and AOT measured by MODIS from August 2004 to July 2008. The convergence of each fit is indicated by $\chi^{2} / \mathrm{DOF}$.

\begin{tabular}{lrrrrr}
\hline & \multicolumn{5}{c}{ Fitted Parameter } \\
\cline { 2 - 6 } Region & $\alpha$ & $\beta$ & $\eta$ & $\varepsilon$ & $\chi^{2}$ /DOF \\
\hline Global & 0.133 & 0.00543 & -0.0661 & 24.039 & 1.7 \\
South America & 0.183 & 0.00308 & -0.0632 & 23.795 & 1.9 \\
Southern Africa & 0.201 & 0.00716 & -0.0740 & 22.684 & 1.8 \\
Northern Africa & 0.259 & 0.00678 & -0.0589 & 23.703 & 1.7 \\
South Asia & 0.230 & 0.0258 & -0.0838 & 25.919 & 4.6 \\
East Asia & 0.144 & 0.0172 & -0.0426 & 24.709 & 7.2 \\
\hline
\end{tabular}

iterations, the best fittings are those for the Global, South America, Southern and Northern African regions. The empirical models for South and East Asia do not fit with the observations as well as the other four regions. The regional differences are discussed below.

\section{Analyses of regional characteristics}

\subsection{Qualitative differences: the BVC plots}

We display $r_{\mathrm{e}}$ as a function of CONV and AOT in Fig. 3 for a number of regions using both observations and the empirical fittings. Comparing with the observations (Fig. 3 leftcolumn), the empirical models (Fig. 3 right-column) approximately capture the broad features of observed $r_{\mathrm{e}}$-CONVAOT relationships. For example, $r_{\mathrm{e}}$, in general, increases with CONV but decreases with AOT, so that the largest $r_{\mathrm{e}}$ occurs when convection $(\mathrm{CONV})$ is strong and pollution (AOT) is low.

At the global scale (Fig. 3a, b), increasing aerosol pollution tends to reduce cloud particle size, while increasing convection tends to enlarge cloud particle size. Strong convection, however, also increases the distributions of aerosols into the UT. Thus, for the same columnar AOT, the UT ice clouds may be more affected by aerosols in regions of stronger CONV, indicated by a steeper gradient of $r_{\mathrm{e}}$ with increasing AOT, than in regions of weaker CONV.

For South America (Fig. 3c, d), the observed $r_{\mathrm{e}}$ increases with increasing convective strength, but varies less monotonically with AOT than in the global case. Large $r_{\mathrm{e}}$ is broadly distributed in low AOT regions, but the largest $r_{\mathrm{e}}$ is not collocated with the cleanest air. One reason may be that cloud particle size can increase with AOT in regions where moisture is abundant and cloud particles continue growing with increasing number concentration of cloud condensation nuclei (e.g. Ackerman et al., 2004). However, such a nonmonotonic behavior is not captured by the empirical fitting, because the AOT dependence is chosen to be a monotonically decreasing function. In regions where CONV is larger than 1 , the observed increase of $r_{\mathrm{e}}$ with CONV is not as sharp as in the global case, while the empirical model appears to produce larger $r_{\mathrm{e}}$ than the observation. Southern Africa (Fig. 3e, f) and Northern Africa (Fig. 3g, h) regions are very similar to each other in that the maximum $r_{\mathrm{e}}$ is much smaller than the global case, resulting in weak $r_{\mathrm{e}}$ gradients for all values of CONV and AOT. It appears that $r_{\mathrm{e}}$ decreases with AOT more rapidly in Southern Africa than in Northern Africa.

South Asia (Fig. 3i, j) is very different from the rest of the geographical regions. The reduction of $r_{\mathrm{e}}$ with AOT is more pronounced both at the low $(<\sim 0.8)$ and high $(>\sim 2)$ ends of 

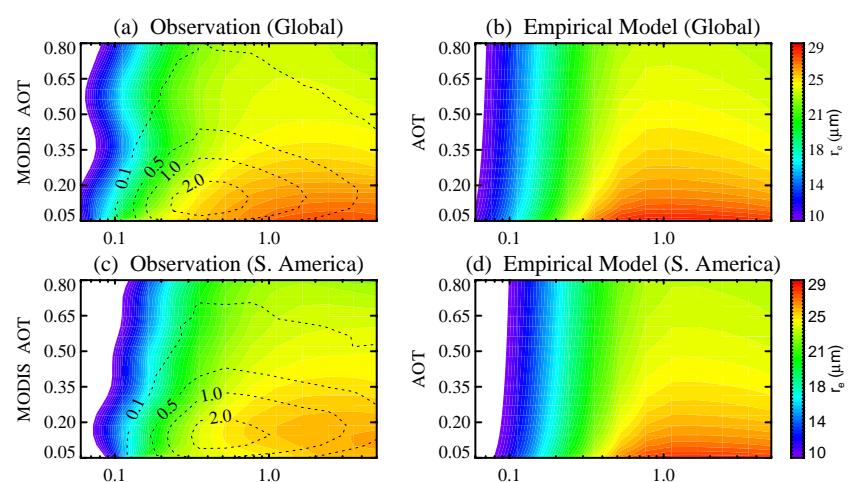

(e) Observation (S. Africa)
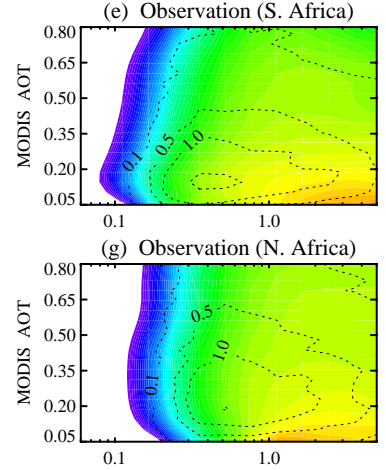

(i) Observation (S. Asia)

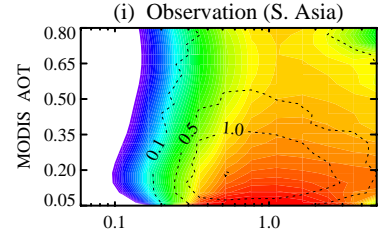

(k) Observation (E. Asia)
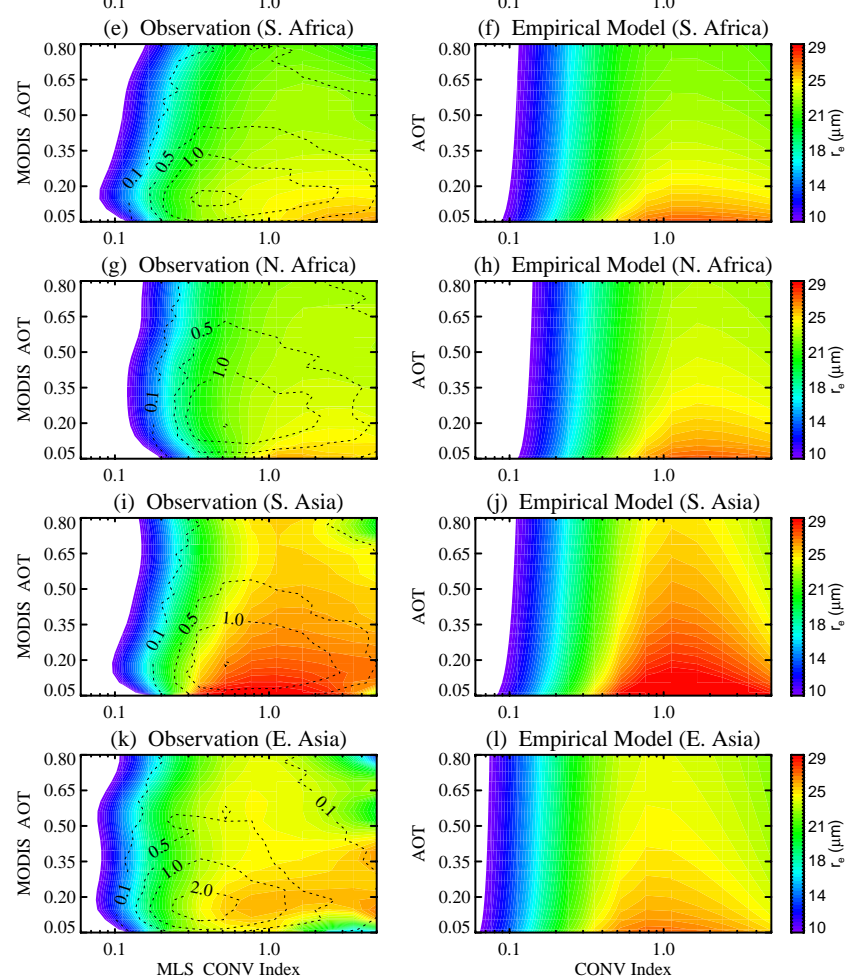

(h) Empirical Model (N. Africa)

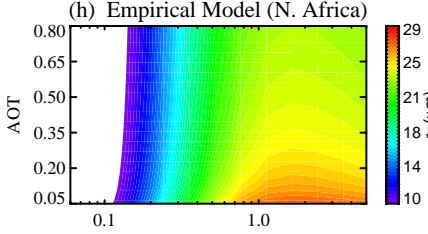

(j) Empirical Model (S. Asia)

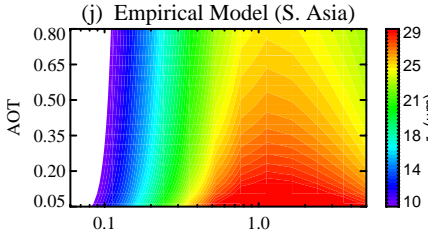

(1) Empirical Model (E. Asia)

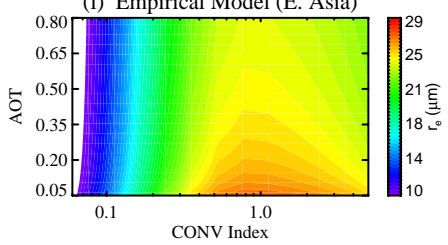

Fig. 3. Left column: Observed $r_{\mathrm{e}}$ as a function of CONV and AOT in various regions. The dotted-lines are the occurrence frequency for each CONV-AOT bin. Right column: Computed $r_{\mathrm{e}}$ as a function of CONV and AOT based on the empirical models for each region.

the CONV values. In the medium CONV values between 0.8 and 2, the reduction of $r_{\mathrm{e}}$ with AOT is slower than in the low and high CONV ranges, resulting in ice clouds having large $(>27 \mu \mathrm{m}) r_{\mathrm{e}}$, extending into the high AOT $(>0.4)$ range. This dependence of aerosol effects on convective regimes may indicate complicated coupling between aerosol forcing and meteorological conditions.

East Asia (Figs. 3k, 1) has very irregular $r_{\mathrm{e}}$ changes with CONV and AOT. First, it seems to share a similar feature to South Asia in the medium CONV range, where the reduction of $r_{\mathrm{e}}$ with AOT is slow. Second, $r_{\mathrm{e}}$ is observed to rapidly increase with AOT in regions where AOT is less than $\sim 0.2$ to 0.3 (Fig. 3k). Increases of both ice and liquid cloud $r_{\mathrm{e}}$ with

AOT in the Southeast Asian regions have been previously reported (e.g. Chylek et al., 2006; Yuan et al., 2008). The first feature is simulated by the empirical model (Fig. 31), while the second feature is not captured, which is the main reason for the large $\chi^{2} / \mathrm{DOF}$ value and poor fitting in this region.

\subsection{Quantitative differences: each term in the empirical model}

The empirical model has several different terms (see Eq. 4). The first term, $[1-\exp (-\mathrm{CONV} / \alpha)]$, represents the growth of $r_{\mathrm{e}}$ with respect to CONV (Fig. 4a): When there is no convection $(\mathrm{CONV} \rightarrow 0$ ), this term approaches 0 . As CONV increases, it grows quickly. For CONV $>1$, this term approaches the maximum of 1 . This increasing effect of convection on $r_{\mathrm{e}}$ is the strongest in Northern Africa and South Asia, indicated by the largest values of $\alpha$, around $0.23-0.26$. The global case yields the smallest $\alpha, 0.13$.

The second term, $1 / \exp (\beta \mathrm{CONV})$, is formulated to model the decrease of $r_{\mathrm{e}}$ with CONV (Fig. 4b), especially at large CONV values. This decreasing effect of CONV on $r_{\mathrm{e}}$ is the strongest in South and East Asia, corresponding to the largest $\beta$. Figure $4 \mathrm{c}$ shows the combination of these two terms, $r_{\text {conv }}=[1-\exp (-\mathrm{CONV} / \alpha)] / \exp (\beta \mathrm{CONV})$, which captures the initial growth of $r_{\text {conv }}$ with CONV, reaching a maximum around $\mathrm{CONV}=1$, and decreasing $r_{\text {conv }}$ when CONV further increases. For CONV $>1$, the decrease of $r_{\text {conv }}$ is most noticeable in South and East Asia. Possible causes for the reduction in $r_{\text {conv }}$ with increasing CONV include: (1) Increased convection distributes more aerosols to the high altitudes in the UT thus affecting ice cloud formation there. For the same columnar AOT, stronger convection may result in increased aerosol effects (reduction of $r_{\mathrm{e}}$ ) on ice clouds; (2) The cloud top is higher in stronger convection thus the MODIS $r_{\mathrm{e}}$ is measured at higher altitude with lower cloud top temperature. It is known that ice cloud formed in colder temperature has smaller particle size (e.g. McFarquhar and Heymsfield, 1997).

The third term, $r_{\text {aot }}=\mathrm{AOT}^{\eta}$, represents the modulation of AOT on $r_{\mathrm{e}}$ (Fig. 4d): increasing aerosol loading increases cloud number density and reduces $r_{\mathrm{e}}$. The differences among the curves for South America, Southern African and Northern Africa are relatively small, suggesting similar aerosol effects in these three regions. The slope of this term is the largest in South Asia and smallest in East Asia as characterized by the largest and smallest values of $(-\eta)$, respectively. The steep slope for South Asia indicates a strong aerosol influence, while the flatness of the curve for East Asia suggests that increasing aerosols in this region have a relatively small impact on the cloud particle size. On the other hand, the larger value of $(-\eta)$, for the same AOT, $r_{\text {aot }}=$ AOT $^{\eta}$ yields larger $r_{\mathrm{e}}$. In this case, $r_{\mathrm{e}}$ is larger for South Asia than East Asia for the same AOT, which may be due to more moisture in the South Asian monsoon region. South America 
(a)

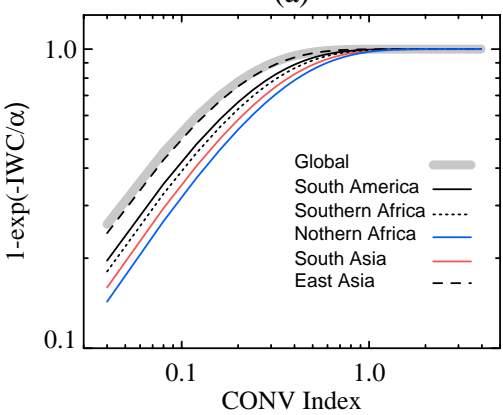

(d)

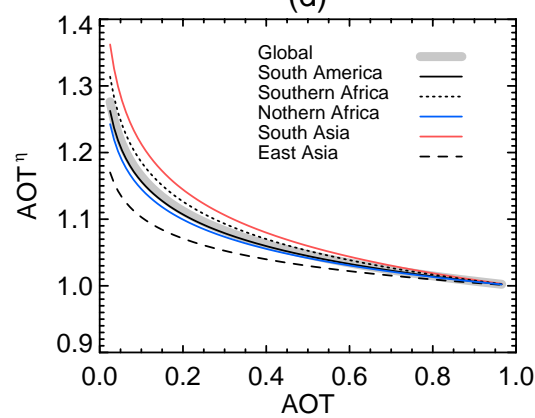

(b)

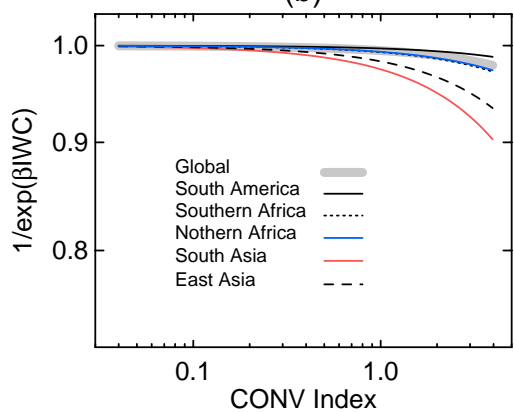

(e)

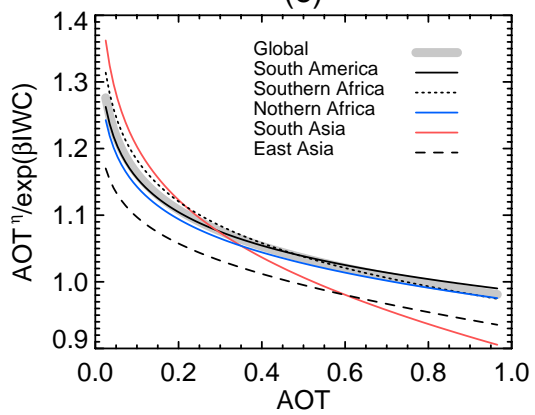

(c)

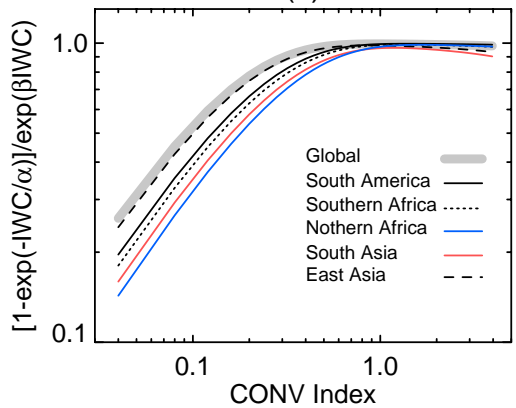

(f) Emprical Model

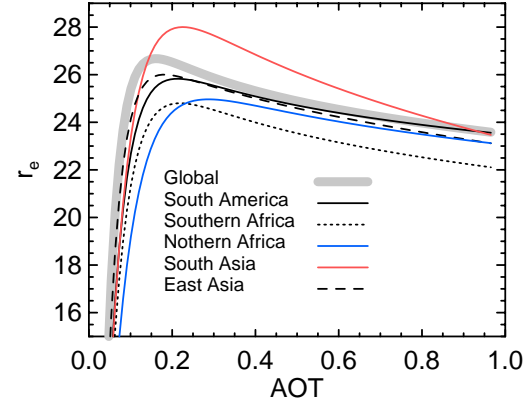

Fig. 4. (a-e): Plots showing how each term (or the combination of two terms) of the empirical models governs $r_{\mathrm{e}}$ in various regions. (f): The modeled $r_{\mathrm{e}}$ as a function of AOT for each region.

and Africa (Northern and Southern) regions have characteristics in-between those of East and South Asia regions, corresponding to a moderate aerosol effect.

Figure $4 \mathrm{e}$ combines the two reduction terms together, $r_{\text {aot }} / \exp (\beta \mathrm{CONV})=\mathrm{AOT}^{\eta} / \exp (\beta \mathrm{CONV})$. South Asia stands out again in Fig. 4e, which shows the strongest reduction rate of $r_{\mathrm{e}}$ with increasing AOT. The combined effects of CONV $\left(r_{\text {conv }}\right)$ and AOT $\left(r_{\text {aot }}\right)$ on $r_{\mathrm{e}}$ as computed by the empirical model (Eq. 4) are illustrated by Fig. 4f, which approximately capture the observed relationships (e.g. Figs. 2b, 3 left column).

\section{Conclusions}

Based on the analysis of 4 years (August 2004 to July 2008) collocated Aura MLS and Aqua MODIS observations, we find that MODIS ice cloud effective radius $\left(r_{\mathrm{e}}\right)$ generally increases with convective intensity but decreases with aerosol loading. We use MLS IWC measurement at $215 \mathrm{hPa}$ to indicate convective strength (CONV) and AOT measurement from MODIS to indicate aerosol loading. Using leastsquares fitting, we obtain an empirical formula for $r_{\mathrm{e}}$ as a function of CONV and AOT, which approximately captures the observed relationships among $r_{\mathrm{e}}, \mathrm{CONV}$ and AOT.

Using this empirical model, we can quantitatively compare the regional differences in the dependence of $r_{\mathrm{e}}$ on CONV and AOT. We find that South Asia and Northern Africa exhibit strong increases of $r_{\mathrm{e}}$ with CONV, while South and East
Asia also approach the saturation effect of $r_{\mathrm{e}}$ with CONV quite quickly, possible due to the prevalence of aerosols there. When convection increases, aerosols are lifted high in the atmosphere, causing a reduction of $r_{\mathrm{e}}$. The South Asia region has the greatest reduction of $r_{\mathrm{e}}$ by unit AOT, with the rate of reduction coefficient is about twice of that in East Asia and 30\% higher than the global average. Whether this strong sensitivity of $r_{\mathrm{e}}$ to aerosol amount in South Asia relates to the aerosol composition, the background aerosol concentration, or the dynamical system, warrants further study. It is also worth noting that the empirical fitting converges relatively poorer in South and East Asia than other regions, suggesting the complexity of aerosol-cloud interactions there.

The empirical model represents our first attempt to derive an analytical formula that captures aerosol effects on ice cloud particle size. The approach demonstrates a framework to use satellite data to quantify the first indirect effect of aerosol on ice clouds for use in climate models. With the better height-resolved aerosol and cloud data from CALIPSO and CloudSat, we will continue this work to provide a heightresolved $r_{\mathrm{e}}$ parameterization for simulating the aerosol effect on cloud particle size.

Acknowledgements. We thank the NASA ACMAP and IDS programs for support. The work was conducted at the Jet Propulsion Laboratory, California Institute of Technology, under contract with NASA.

Editedt by: B. N. Duncan 


\section{References}

Ackerman, A. C., Kirkpatrick, M. P., Stevens, D. E., and Toon, O. B.: The impact of humidity above stratiform clouds on indirect aerosol climate forcing, Nature, 432, 1014-1017, 2004.

Albrecht, B. A.: Aerosols, cloud microphysics, and fractional cloudiness, Science, 245, 1227-1230, 1989.

Chylek, P., Dubey, M. K., Lohmann, U., Ramanathan, V., Kaufman, Y. J., Lesins, G., Hudson, J., Altmann, G., and Olsen, S.: Aerosol indirect effect over the Indian Ocean, Geophys. Res. Lett., 33, L06806, doi:10.1029/2005GL025397, 2006.

Devasthale, A. and Fueglistaler, S.: A climatological perspective of deep convection penetrating the TTL during the Indian summer monsoon from the AVHRR and MODIS instruments, Atmos. Chem. Phys., 10, 4573-4582, doi:10.5194/acp-10-45732010, 2010.

Evans, K. F. and Stephens, G. L.: Microwave radiative transfer through clouds composed of realistically shaped ice crystals. Part I: Single scattering properties, J. Atmos. Sci., 52, 2041-2057, 1995.

Jiang, J. H., Livesey, N. J., Su, H., Neary, L., McConnell, J. C., and Richards, N. A.: Connecting surface emissions, convective uplifting, and long-range transport of carbon monoxide in the upper-troposphere: New observations from the Aura MLS, Geophys. Res. Lett., 34, L18812, doi:10.1029/2007GL030638, 2007.

Jiang, J. H., Su, H., Schoeberl, M., Massie, S. T., Colarco, P., Platnick, S., and Livesey, N.: Clean and polluted clouds: relationships among pollution, ice cloud and precipitation in South America, Geophys. Res. Lett., 35, L14804, doi:10.1029/2008GL034631, 2008.

Jiang, J. H., Su, H., Massie, S. T., Colarco, P. R., Schoeberl, M. R., and Platnick, S.: Aerosol-CO relationship and aerosol effect on Ice cloud particle size: Analyses from Aura MLSand Aqua MODIS observations, J. Geophys. Res., 114, D20207, doi:10.1029/2009JD012421, 2009.

Jiang, J. H., Su, H., Pawson, S., Liu, H. C., Read, W., Waters, J. W., Santee, M., Wu, D. L., Schwartz, M., Livesey, N., Lambert, A., Fuller, R., and Lee, J. N.: Five-year (2004-2009) Observations of Upper Tropospheric Water Vapor and Cloud Ice from MLS and Comparisons with GEOS-5 analyses, J. Geophys. Res., 115, D15103, doi:10.1029/2009JD013256, 2010.

Kazuaki, Y., Hideji, K., Takehiko, S., and Noriyuki, N.: A numerical study on the detrainment of tracers by cumulus convection in TOGA COARE, J. Meteo. Soc. Japan, 82(3), 861-878, 2004.

Liu, C.: Geographical and seasonal distribution of tropical tropopause thin clouds and their relation to deep convection and water vapor viewed from satellite measurements, J. Geophys. Res., 112, D09205, doi:10.1029/2006JD007479, 2007.

Lohmann, U. and Feichter, J.: Global indirect aerosol effects: a review, Atmos. Chem. Phys., 5, 715-737, doi:10.5194/acp-5-7152005, 2005.

McFarquhar, G. M. and Heymsfield, A. J.: Parameterization of tropical cirrus ice crystal size distributions and implications radiative transfer: Results from CEPEX, J. Atmos. Sci., 54, 2187-2200, 1997.

Matrosov, S. Y., Orr, B. W., Kropfli, R. A., and Snider, J. B.: Retrieval of vertical profiles of cirrus cloud microphysical parameters from Doppler radar and infrared radiometer measurements, J. Appl. Meteor., 33, 617-626, 1994.

Menon, S., Hansen, J., Nazarenko, L., and Luo, Y.: Climate Effects of Black Carbon Aerosols in China and India, Science, 27, 22502253 doi:10.1126/science.1075159, 2002.

Mitchell, D. L., Chai, S. K., Liu, Y., Heymsfield, A. J., and Dong, Y.: Modeling cirrus clouds. Part I: Treatment of bimodal size spectra and case study analysis, J. Atmos. Sci., 53, 2952-2966, 1996.

Penner, J. E., Quaas, J., Storelvmo, T., Takemura, T., Boucher, O., Guo, H., Kirkevåg, A., Kristjánsson, J. E., and Seland, Ø.: Model intercomparison of indirect aerosol effects, Atmos. Chem. Phys., 6, 3391-3405, doi:10.5194/acp-6-3391-2006, 2006.

Platnick, S.: Vertical photon transport in cloud remote sensing problems, J. Geosphys, Res., 105(D18), 22919-22935, 2002.

Platnick, S., King, M. D., Ackerman, S. A., Menzel, W. P., Baum, B. A., Riédi, J. C., and Frey, R. A.: The MODIS cloud products: Algorithms and examples from terra, IEEE Trans. Geosci. Remote Sens., 41, 459-473, 2003.

Platt, C. M. R.: A parameterization of the visible extinction coefficient in terms of the ice/water content, J. Atmos. Sci., 48, 2083-2098, 1997.

Remer, L. A., Kaufman, Y. J., Tanré, D., Mattoo, S., Chu, D. A., Martins, J. V., Li, R.-R., Ichoku, C., Levy, R. C., Kleidman, R. G., Eck, T. F., Vermote, E., and Holben, B. N.: The MODIS aerosol algorithm, products and validation, J. Atmos. Sci., 62, 947-973, (2005).

Rienecker, M. M., Suarez, M. J., Todling, R., Bacmeister, J., Takacs, L., Liu, H.-C., Gu, W., Sienkiewicz, M., Koster, R. D., Gelaro, R., Stajner, I., and Nielsen, J. E.: The GEOS?-5 data assimilation system - Documentation of versions 5.0.1, 5.1.0, and 5.2.0, NASA Tech. Memo., TM-2008-104606, 27, 92 pp., 2008.

Sherwood, S. C.: Aerosols and ice particle size in tropical cumulonimbus, J. Climate, 15, 1051-1063, 2002.

Su, H., Read, W. G., Jiang, J. H., Waters, J. W., Wu, D. L., and Fetzer, E. J.: Enhanced positive water vapor feedback associated with tropical deep convection: New evidence from Aura MLS, Geophys. Res. Lett., 33, L05709, doi:10.1029/2005GL025505, 2006.

Su, H., Jiang, J. H., Liu, X., Penner, J. E., Read, W. G., Massie, S. T., Schoeberl, M. R., Colarco, P., Livesey, N. J., and Santee, M. L.: Observed increase of TTL temperature and water vapor in polluted clouds over Asia, J. Climate, in press, 2011.

Twomey, S.: Atmospheric Aerosols, Elsevier Scientific, Amsterdam, 302 pp., 1977.

Yuan, T., Li, Z., Zhang, R., and Fan, J.: Increase of cloud droplet size with aerosol optical depth: An observation and modeling study, J. Geophys. Res., 113, D04201, doi:10.1029/2007JD008632, 2008.

Wu, D. L., Jiang, J. H., Read, W. G., Austin, R. T., Davis, C. P., Lambert, A., Stephens, G. L., Vane, D. G., and Waters, J. W.: Validation of the Aura MLS cloud ice water content measurements, J. Geophys. Res., 113, D15S10, doi:10.1029/2007JD008931, 2008.

Wu, W.-S., Purser, R. J., and Parrish , D. F.: Three dimensional variational analysis with spatially inhomogeneous covariances, Mon. Weather Rev., 130, 2905-2916, doi:10.1175/1520-0493, 2002.

Zhang, Z., Platnick, S., Yang, P., Heidinger, A. K., and Comstock, J.: Effects of ice particle size vertical inhomogeneity on the passive remote sensing of ice clouds, J. Geophys. Res., 115, D17203, doi:10.1029/2010JD013835, 2010. 